\title{
Knowledge of Adverse Drug Reaction Reporting and the Pharmacovigilance of Biological Medicines: A Survey of Healthcare Professionals in Ireland
}

\author{
J. O'Callaghan ${ }^{1,2,3} \cdot$ B. T. Griffin ${ }^{1,2} \cdot$ J. M. Morris ${ }^{1} \cdot$ Margaret Bermingham $^{2}$
}

Published online: 2 May 2018

(c) The Author(s) 2018

\begin{abstract}
Background In Europe, changes to pharmacovigilance legislation, which include additional monitoring of medicines, aim to optimise adverse drug reaction (ADR) reporting systems. The legislation also makes provisions related to the traceability of biological medicines.

Objective The objective of this study was to assess (i) knowledge and general experience of ADR reporting, (ii) knowledge, behaviours, and attitudes related to the pharmacovigilance of biologicals, and (iii) awareness of additional monitoring among healthcare professionals (HCPs) in Ireland. Methods Hospital doctors $(n=88)$, general practitioners (GPs) $(n=197)$, nurses $(n=104)$ and pharmacists $(n=309)$ completed an online questionnaire.

Results There were differences in mean knowledge scores relating to ADR reporting and the pharmacovigilance of biologicals among the HCP groups. The majority of HCPs who use biological medicines in their practice generally record biologicals by brand name but practice behaviours relating to batch number recording differed between some professions. HCPs consider batch number recording to be valuable but also regard it as being more difficult than brand name recording. Most respondents were aware of the
\end{abstract}

Electronic supplementary material The online version of this article (https://doi.org/10.1007/s40259-018-0281-6) contains supplementary material, which is available to authorized users.

Margaret Bermingham

Margaret.bermingham@ucc.ie

1 Regulatory Science Ireland, c/o School of Pharmacy, University College Cork, Cork, Ireland

2 School of Pharmacy, University College Cork, Cork, Ireland

3 Health Products Regulatory Authority, Kevin O'Malley House, Earlsfort Centre, Earlsfort Terrace, Dublin 2, Ireland concept of additional monitoring but awareness rates differed between some groups. Among those who knew about additional monitoring, there was higher awareness of the inverted black triangle symbol among pharmacists (>86.4\%) compared with hospital doctors (35.1\%), GPs $(35.6 \%)$, and nurses $(14.9 \%)$. Hospital pharmacists had more experience and knowledge of ADR reporting than other practising HCPs.

Conclusion This study highlights the important role hospital pharmacists play in post-marketing surveillance. There is a need to increase pharmacovigilance awareness of biological medicines and improve systems to support their batch traceability.

\section{Key Points}

There were differences in experience and knowledge of ADR reporting as well as confidence in the ability to report ADRs among hospital doctors, general practitioners, nurses, and pharmacists

Healthcare-professional awareness of additional monitoring was high. However, pharmacists were significantly more aware of the inclusion of the inverted black triangle symbol $\boldsymbol{\nabla}$ on the product information of such medicines than hospital doctors, general practitioners, and nurses

Overall, healthcare professionals were more familiar with the term biological medicine than biosimilar medicine. Biological medicines are typically recorded by brand name but batch numbers are recorded to a lesser extent. This may negatively impact the traceability of biologicals to batch level in ADR reporting databases 


\section{Introduction}

Pharmacovigilance refers to the ongoing assessment of a medicine's safety throughout its lifecycle [1]. Adverse drug reaction (ADR) reporting is a key source of information for safety signal detection activities and is useful in the identification of rare adverse events [2]. However, it is estimated that only $6 \%$ of ADRs are reported [3]. Factors that may contribute to underreporting among healthcare professionals (HCPs) include knowledge, negative attitudes, lack of time and motivation [4]. Lack of standardised reporting processes and gaps in healthcare information systems also contribute to underreporting [5]. New pharmacovigilance legislation, which came into effect in Europe in July 2012, resulted in specific changes related to ADR reporting including provision for direct patient reporting of ADRs and additional monitoring of medicines [6]. Additional monitoring aims to encourage ADR reporting, thereby allowing additional safety data to be gathered for medicines containing new active substances or medicines with emerging safety issues. The additional monitoring status of a medicine is indicated by the presence of an inverted black triangle symbol $\boldsymbol{\nabla}$, accompanied by an explanatory statement encouraging the reporting of ADRs, on the Summary of Product Characteristics (SmPC) and the Package Leaflet (PL) [7]. The revised pharmacovigilance legislation also made provisions related to the traceability of biological medicines. As such, brand name and batch numbers should be included in ADR reports for biological medicines [8].

Biological medicines pose specific challenges for pharmacovigilance. A recent guideline published by the European Medicines Agency (EMA) highlights four key considerations for the pharmacovigilance of biologicals; namely immunogenicity, manufacturing variability, stability/cold chain requirements and product traceability [9]. Biological medicines are inherently variable and although different batches of the same biological medicine are not identical, the quality of each batch is tightly controlled to ensure the safety and efficacy of the medicine [10]. However, necessary manufacturing process changes [10] can impact quality attributes of the biological and this can occur unbeknownst to healthcare professionals and patients [11]. In rare instances, these changes can have unforeseen effects on the immunogenicity of a product [12]. Biological medicines including biosimilars are becoming increasingly available [13]. Biosimilars are distinct from the generics of chemical medicines as, owing to the complexities of biological substances and their manufacturing processes, biosimilars are not completely identical to the original medicine on which they are based (reference medicine). Similarity to the reference medicine is demonstrated through a rigorous comparability exercise conducted at the quality, pre-clinical and clinical levels [14]. All newly approved biological medicines, including biosimilars, are subject to additional monitoring for a period of 5 years after approval.

The traceability of biologicals is essential so that the impact of suspected ADRs can be properly evaluated to both product and batch level. Contrary to naming approaches taken in the United States [15], a biosimilar in Europe has the same international non-proprietary name (INN) as its reference medicine, even though it is not its generic equivalent. Therefore, inclusion of the brand name in ADR reports allows differentiation to be made between products. Product-specific pharmacovigilance also allows changes in product quality or characteristics that may result in clinically meaningful differences arising between products with the same INN $[9,16]$ to be captured. Traceability to batch level is necessary to signal batch-specific issues or flag adverse reactions attributable to manufacturing process changes [17]. Consequently, HCPs are advised to systematically record and report detailed exposure information for all biological medicines [18].

In most cases, biologicals are prescribed in specialised hospital settings; however, patients receiving these medicines are usually cared for by multidisciplinary teams composed of hospital doctors, nurses, general practitioners (GPs) and pharmacists. Biological medicines have specific pharmacovigilance considerations and all newly approved biologicals are subject to additional monitoring. An appreciation of these considerations by HCPs helps to ensure the safe and effective use of biological medicines. Several studies on knowledge of ADR reporting among HCPs have been conducted previously [19-23] and the findings suggest knowledge of, as well as communication and training on ADR reporting could be improved. However, there appear to be no studies that address HCP knowledge of the pharmacovigilance of biological medicines. It is also not known if HCPs in Europe are aware of additional monitoring. A survey of a diverse group of HCPs in Ireland was conducted in order to assess and compare (i) knowledge and general experience of ADR reporting, (ii) knowledge, behaviours and attitudes related to the pharmacovigilance of biologicals and (iii) awareness of additional monitoring.

\section{Methods}

\subsection{Questionnaire Design}

A questionnaire was developed based on previously published studies [13, 19, 24-27]. The questionnaire wording was agreed by a panel of experts with backgrounds in 
regulation, clinical pharmacy, pharmacovigilance, academia and regulatory affairs. The face validity of the questionnaire was tested in a pilot study using a convenience sample of 18 HCPs. Minor modifications were made to some of the questions after the pilot study to improve clarity. On the basis of the pilot study it was estimated that the questionnaire would take 5-10 min to complete.

The questionnaire consisted of an information letter with informed consent statement and a total of 26 questions, including questions consisting of multiple choice statements. Not all questions had to be answered as respondents were directed towards questions that were relevant to them using an in-built 'survey-monkey logic' tool. Two sets of closed questions were used to measure knowledge. Each set of closed questions contained eight statements and respondents were asked to respond 'yes', 'no' or 'don't know' to each statement. The first set related to ADR reporting. Seven of the eight statements had been used in previous surveys of medical students, pharmacy students and pharmacists $[19,24,25]$. The second set of closed questions contained eight statements relating to specific pharmacovigilance considerations for biological medicines. A brief explanation of the term biological medicine was provided. The questionnaire is provided in the electronic supplementary material (ESM).

Two dichotomous closed questions were used to establish respondent's knowledge of the concept of 'additional monitoring' (a brief explanation of this term was provided) and the presence of the inverted black triangle $\boldsymbol{\nabla}$ on product information. A 5-point Likert scale was used to establish awareness and behaviours related to additional monitoring among HCPs who had knowledge of this concept. Familiarity with the terms 'biological medicine' and 'biosimilar medicine' was established using two multiplechoice questions. Respondents who prescribed, dispensed or administered biological medicines were asked questions related to traceability of biologicals in their practice. Attitudes related to the value and difficulty of brand name and batch number recording were assessed on two different scales. The first scale was anchored by 'Worthless (1) to Valuable (7)' and the second scale by 'Easy (1) to Difficult (7)'.

\subsection{Questionnaire Distribution}

The questionnaire was made available to HCPs online (hosted at http://www.surveymonkey.com) from May to July 2017. The HCP groups were hospital doctors (practising at consultant [specialist] or non-consultant level), GPs (doctors working in primary care), nurses and pharmacists. Hospital doctors and GPs were invited to complete the questionnaire in emails circulated to members by the Royal College of Physicians in Ireland and the Irish
College of GPs, respectively. The Office of Nursing and Midwifery Services in the Irish Health Service Executive requested senior nurses to distribute the survey link to their nursing staff. Finally, the Pharmaceutical Society of Ireland provided details of members' email addresses to one member of the research team (JOC). One reminder email was sent to nurses and GPs. Due to project time constraints, hospital doctors and pharmacists did not receive any reminders. No honorarium was provided to respondents.

\subsection{Statistical Analysis}

All data were analysed using IBM SPSS Statistics Version 23. Each respondent's knowledge level relating to (i) ADR reporting and (ii) the pharmacovigilance of biologicals was calculated by summing all correct items and dividing by the total number of items. Comparison between categorical variables was performed using the Chi square test for independence. Independent $t$ tests or one-way Analysis of Variance (ANOVA) was used to compare mean knowledge scores with baseline characteristics. The Mann-Whitney $U$ test or the Kruskal-Wallis test were used to confirm findings in cases where not all assumptions of the parametric tests were met. A 5\% significance level applies throughout all hypothesis testing. A Bonferroni correction was applied when multiple group comparisons were made. In cases where 15 comparisons were made, the alpha level was adjusted to 0.003 , where five comparisons were made, the alpha level was 0.01 .

\subsection{Analysis of Adverse Drug Reaction (ADR) Database}

Information on the sources of suspected new ADR reports was obtained from annual reports published by the Health Products Regulatory Authority (HPRA, formerly Irish Medicines Board) for a 5-year period (2012-2016). Reports are published on the HPRA website [28]. ADR reports for biological medicines containing epoetins, filgrastims and infliximab were extracted from the HPRA ADR database. The reports covered a 5-year period (2013-2017). These substances were chosen as both reference and biosimilar products were available on the Irish marketplace. Reports were reviewed for inclusion of brand name and batch number details.

\subsection{Ethical Considerations}

The research study was approved by the Social Research Ethics Committee (SREC) in University College Cork, Ireland (Log 2017-039). 


\section{Results}

A total of 821 responses were received. The email invite was sent to a total of 2360 hospital doctors (97 responses received), 2900 GPs (238 responses received) and 5837 pharmacists (349 responses received). This corresponded to response rates of 4, 8 and $6 \%$ for hospital doctors, GPs and pharmacists respectively. Responses were also received from 121 nurses. Response rates could not be calculated for nurses as it could not be determined how many senior nurses forwarded the link to their nursing staff. A total of 16 respondents categorised themselves as 'other'. There were 708 complete responses. Of this number, eight did not meet the inclusion criteria (i.e. hospital doctor, GP, nurse or pharmacist) and were excluded from the final analysis. Two pharmacists that did not provide details of their practice area were also excluded. Consequently, responses from 698 HCPs were analysed.

\subsection{Demographics}

Respondents were grouped according to profession. Pharmacists were further categorised according to their practice setting. Those pharmacists who did not work in community and hospital pharmacies were classified as 'other' pharmacists. This group generally represented pharmacists working in industry, academia or regulation, and as such this group were not considered to be practising HCPs. A total of 88 hospital doctors completed the questionnaire. The majority of hospital doctors were consultants (specialists) $(67 \%, n=59)$ and $33 \%(n=29)$ were non-consultant hospital doctors. The hospital doctors came from a wide variety of specialities (see Table S1, ESM). Almost half $(47 \%, n=42)$ worked in specialities where biological medicines are commonly used. Only one hospital doctor did not prescribe medicines to their patients. Nurses also came from a variety of backgrounds (see Table S2, ESM). Nurses had the most experience, with over $74 \%$ of nurses surveyed having 20 or more years' professional experience. The 'other' pharmacists were the least experienced, with $44 \%$ of this group having $<10$ years of experience. Respondents were also asked if biological medicines were prescribed, dispensed or administered in their practice. Group demographics are summarised in Table 1.

The majority of respondents knew that ADRs could be reported directly to the HPRA. Analysis by profession found that $60.6 \%(n=63)$ of nurses, $82.2 \%(n=162)$ of GPs, $86.4 \%(n=76)$ of hospital doctors, $93.5 \%(n=158)$ of community pharmacists, $96.2 \%(n=51)$ of 'other' pharmacists and $98.9 \%(n=86)$ of hospital pharmacists knew this. Nurses had lower awareness of this fact than each of the other groups $(p<0.001$ in all cases, Chi square test for independence). GPs were also less aware of this than community or hospital pharmacists $(p=0.002$ and $p<0.001$, respectively, Chi square test for independence).

\subsection{Sources of ADR Reports}

The HPRA received an average of 2910 ADR reports annually over a 5-year period (2012-2016). On average, $26 \%$ of reports came directly from HCPs. Reports also came from pharmaceutical companies $(67 \%)$, patients $(5 \%)$, others $(2 \%)$ and clinical trials $(1 \%)$. A breakdown of reports is provided in Table S3 (see ESM). Reports submitted by pharmaceutical companies would initially have been notified to them by HCPs and members of the public.

\subsection{ADR Reporting Experience}

Nurses had the least experience of ADR reporting, whereas hospital pharmacists had the most (Fig. 1). There was no statistically significant difference in the proportions of hospital doctors, GPs, community and 'other' pharmacists with no experience of ADR reporting ( $p=0.247$, Chi square test for independence). Those with longer professional experience were more likely to have reported an ADR on one or more occasions. There was a significantly higher proportion of non-reporters in those who had $<10$ years' experience compared with those who had $>10$ years' experience $(59.9 \%$ vs $35.8 \%, p<0.001$, Chi square test for independence).

\subsection{Knowledge of ADR Reporting}

Overall responses to the ADR knowledge items are provided in Table 2 and the sub-group analyses are presented in Table S4 (see ESM). The average knowledge level across all eight items was 5.66 correct items out of 8 (SD 1.60). Responses to some of the individual knowledge items varied across HCPs (Table S4, see ESM) and this is indicated by differences in mean knowledge score between groups ( $p<0.001$, one-way ANOVA) (Table 3).

Mean knowledge scores were also associated with previous experience of ADR reporting $(p<0.001$, one-way ANOVA). Tukey post-hoc analysis $(\alpha=0.05)$ found that those who had reported an ADR more than three times in the past had significantly higher knowledge scores $(6.46$, SD 1.24) than those who had never reported an ADR (5.31, SD 1.68), those who had reported an ADR once (5.47, SD 1.59) and those who had reported an ADR on two or three occasions (5.85, SD 1.47). There was no association 
Table 1 Healthcare professional demographics

\begin{tabular}{|c|c|c|c|c|c|c|c|}
\hline Profession & $\begin{array}{l}\text { Hospital } \\
\text { doctor }^{\mathrm{a}}\end{array}$ & $\begin{array}{l}\text { General } \\
\text { practitioner }\end{array}$ & Nurse $^{b}$ & $\begin{array}{l}\text { Community } \\
\text { pharmacist }\end{array}$ & $\begin{array}{l}\text { Hospital } \\
\text { pharmacist }\end{array}$ & $\begin{array}{l}\text { 'Other' } \\
\text { pharmacist }^{\mathrm{c}}\end{array}$ & Total \\
\hline Group size $(n)$ & 88 & 197 & 104 & 169 & 87 & 53 & 698 \\
\hline \multicolumn{8}{|c|}{ Biological medicines used in practice, $\%(n)$} \\
\hline Yes & $78.4(69)$ & $74.2(144)$ & $52.9(54)$ & $88.7(149)$ & $83.9(73)$ & $29.4(15)$ & $73.0(504)$ \\
\hline No & $18.2(16)$ & $19.1(37)$ & $21.6(22)$ & $9.5(16)$ & $13.8(12)$ & $49.0(25)$ & $18.6(128)$ \\
\hline Don’t know & $3.4(3)$ & $6.7(13)$ & $25.5(26)$ & $1.8(3)$ & $2.3(2)$ & $21.6(11)$ & $8.4(58)$ \\
\hline \multicolumn{8}{|c|}{ Years in practice, $\%(n)$} \\
\hline$<5$ & $10.2(9)$ & $17.3(34)$ & $3.8(4)$ & $13.6(23)$ & $4.6(4)$ & $20.8(11)$ & $12.2(85)$ \\
\hline $5-9$ & $13.6(12)$ & $15.7(31)$ & $1.9(2)$ & $21.3(36)$ & 21.8 (19) & $22.6(12)$ & $16.0(112)$ \\
\hline 10-19 & $31.8(28)$ & $23.4(46)$ & $20.2(21)$ & $31.4(53)$ & $40.2(35)$ & $26.4(14)$ & $28.2(197)$ \\
\hline $20-29$ & $21.6(19)$ & $22.8(45)$ & $39.4(41)$ & $18.9(32)$ & $24.1(21)$ & 20.8 (11) & $24.2(169)$ \\
\hline$>30$ & 22.7 (20) & $20.8(41)$ & $34.6(36)$ & $14.8(25)$ & $9.2(8)$ & $9.4(5)$ & 19.3 \\
\hline
\end{tabular}

ESM electronic supplementary material

${ }^{a}$ Hospital doctors practised in a wide variety of specialities—see Table S1 in the ESM

${ }^{\mathrm{b}}$ Nurses came from a wide variety of specialities-see Table S2 in the ESM

' 'Other pharmacists' were not considered to be practising healthcare professionals. This group worked in industry $(n=22)$, academia $(n=12)$, administration $(n=1)$, defence forces $(n=1)$, Health Service Executive $(n=5)$, medicines information $(n=2)$, primary care $(n=1)$, regulatory $(n=7)$, representative organisation $(n=1)$ and retired $(n=1)$

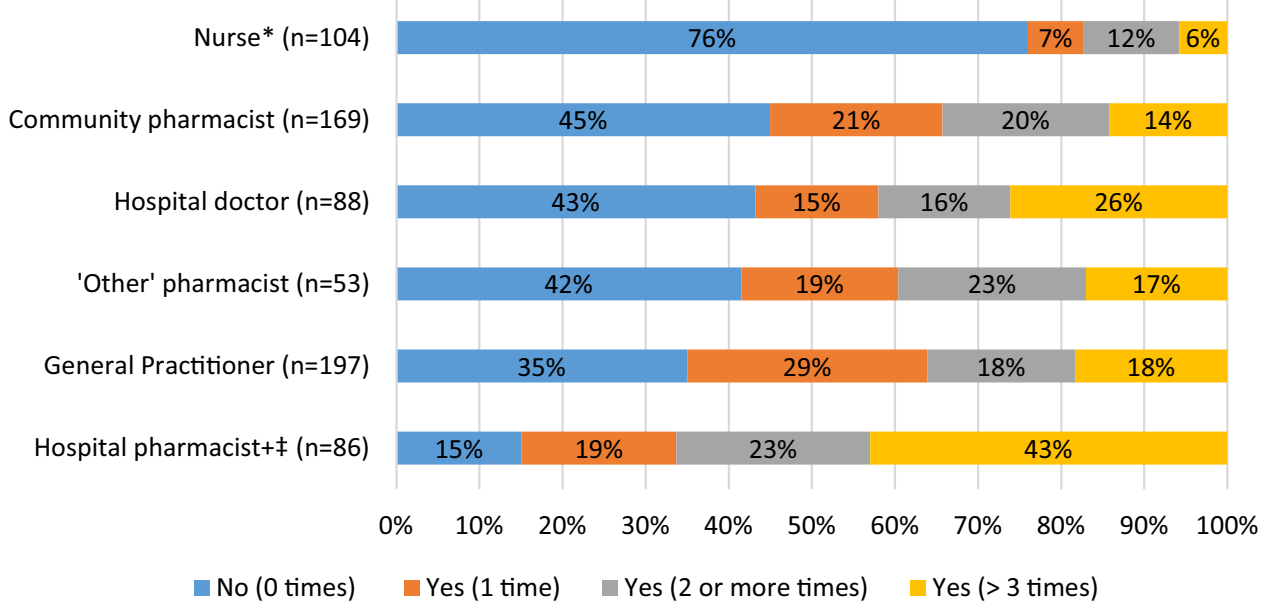

Fig. 1 Differences in adverse drug reaction reporting experience among healthcare professionals. Survey question: "Have you ever reported an adverse reaction?" Reporting rates compared using Chi square test for independence. A Bonferroni correction was applied. Asterisk: the proportion of non-reporters in the nurse group was higher than non-reporting proportions in each of the other groups $(p<0.001$ in all cases). Plus sign: the proportion of non-reporters in

between ADR knowledge scores and duration of professional experience ( $p=0.870$, one-way ANOVA).

The majority of respondents agreed that they have adequate knowledge to report ADRs, however some differences between groups were observed (Fig. 2). the hospital pharmacist group was lower than non-reporting proportions in each of the other groups ( $p \leq 0.001$ in all cases). Double dagger: a higher proportion of hospital pharmacists had reported an ADR on more than three occasions when compared with general practitioners $(p<0.001)$, nurses $(p<0.001)$, community pharmacists $(p<0.001)$ and 'other' pharmacists $(p=0.003)$

\subsection{Familiarity with the Terms Biological Medicine and Biosimilar Medicine}

Survey respondents were asked how familiar they were with the term (i) biological medicine and (ii) biosimilar medicine. Differences in familiarity rates across groups were observed (Table 4). 
Table 2 Adverse drug reaction reporting: responses to individual knowledge items

\begin{tabular}{|c|c|c|c|c|}
\hline Question $^{\mathrm{a}}$ & $n$ & $\begin{array}{l}\% \\
\text { correct }\end{array}$ & $\begin{array}{l}\% \\
\text { incorrect }\end{array}$ & $\begin{array}{l}\% \text { don't } \\
\text { know }\end{array}$ \\
\hline All serious ADRs are known before a medicine is marketed (no) & 696 & 86.4 & 8.0 & 5.6 \\
\hline HCPs should report serious ADRs even if uncertain that the medicine caused the event (yes) & 698 & 89.0 & 2.4 & 8.6 \\
\hline You have adequate knowledge on how to report ADRs (yes) & 697 & 60.0 & 30.8 & 9.2 \\
\hline One case reported by an HCP does not contribute much to knowledge on medicine risks (no) & 696 & 82.5 & 8.0 & 9.5 \\
\hline $\begin{array}{l}\text { HCPs should report serious ADRs even if they do not have all the details of the event (e.g. complete } \\
\text { patient history, demographic data) (yes) }\end{array}$ & 696 & 78.2 & 10.3 & 11.5 \\
\hline HCPs should report ADRs associated with overdose, misuse or error (yes) & 695 & 60.7 & 15.0 & 24.3 \\
\hline Patients can report ADRs independent of a HCP (yes) & 697 & 63.0 & 6.0 & 31.0 \\
\hline HPRA will not disclose an ADR reporter's identity in response to a request from the public (yes) & 696 & 45.7 & 7.5 & 46.8 \\
\hline
\end{tabular}

$A D R$ adverse drug reaction, $H C P$ healthcare professional, HPRA Health Products Regulatory Authority

${ }^{\mathrm{a}}$ Correct answer is shown in brackets

Table 3 Mean knowledge scores relating to adverse drug reaction reporting and the pharmacovigilance of biological medicines among healthcare professional groups

\begin{tabular}{|c|c|c|c|}
\hline Profession & $n$ & Mean knowledge score ${ }^{\mathrm{a}}$ out of 8 & Standard deviation \\
\hline \multicolumn{4}{|c|}{ Adverse drug reaction reporting } \\
\hline Hospital doctor & 88 & 5.45 & 1.58 \\
\hline General practitioner $^{\mathrm{b}}$ & 193 & 5.12 & 1.57 \\
\hline Nurse & 100 & 5.49 & 1.54 \\
\hline Community pharmacist & 166 & 5.69 & 1.53 \\
\hline Hospital pharmacist ${ }^{\mathrm{c}}$ & 87 & 6.30 & 1.37 \\
\hline 'Other' pharmacist ${ }^{\mathrm{d}}$ & 52 & 7.17 & 1.13 \\
\hline Total & 686 & 5.66 & 1.60 \\
\hline \multicolumn{4}{|c|}{ Pharmacovigilance of biological medicines } \\
\hline Hospital doctor & 85 & 6.25 & 1.41 \\
\hline General practitioner $^{\mathrm{e}}$ & 192 & 5.50 & 1.84 \\
\hline Nurse $^{\mathrm{f}}$ & 99 & 4.41 & 1.67 \\
\hline Community pharmacist & 167 & 5.97 & 1.68 \\
\hline Hospital pharmacist ${ }^{\mathrm{g}}$ & 85 & 6.94 & 1.15 \\
\hline 'Other' pharmacist ${ }^{\mathrm{h}}$ & 53 & 7.08 & 1.1 \\
\hline Total & 681 & 5.85 & 1.78 \\
\hline
\end{tabular}

Data is compared using 1-way ANOVA with post-hoc analysis using Tukey test $(\alpha=0.05)$

$A D R$ adverse drug reaction

${ }^{a}$ Knowledge scores were calculated from responses to eight knowledge items on (i) ADR reporting and (ii) pharmacovigilance of biological medicines. A correct answer was given a score of 1 . An incorrect answer or a 'don't know' response was given a score of 0

${ }^{\mathrm{b}}$ General practitioners had lower mean knowledge scores relating to ADR reporting than community pharmacists

${ }^{\mathrm{c}}$ Hospital pharmacists had higher mean knowledge scores relating to ADR reporting than hospital doctors, general practitioners, nurses and community pharmacists

d'Other' pharmacists had higher mean knowledge scores relating to ADR reporting than all other healthcare professional groups

${ }^{\text {e}}$ General practitioners had lower mean knowledge scores relating to the pharmacovigilance of biologicals than hospital doctors, hospital pharmacists and 'other' pharmacists

${ }^{f}$ Nurses had lower mean knowledge scores relating to the pharmacovigilance of biologicals than other healthcare professional groups

${ }^{\mathrm{g}}$ Hospital pharmacists had higher mean knowledge scores relating to the pharmacovigilance of biologicals than community pharmacists and hospital doctors

h'Other' pharmacists had higher mean knowledge scores than community pharmacists and hospital doctors 
Fig. 2 Healthcare professional self-perception of their own knowledge of adverse drug reaction (ADR) reporting. Survey question: "You have adequate knowledge on how to report ADRs?" Reporting rates compared using Chi square test. A Bonferroni correction was applied. *Higher proportions of both hospital pharmacists and other pharmacists agreed with this statement than hospital doctors, general practitioners, nurses and community pharmacists $(p \leq 0.001)$

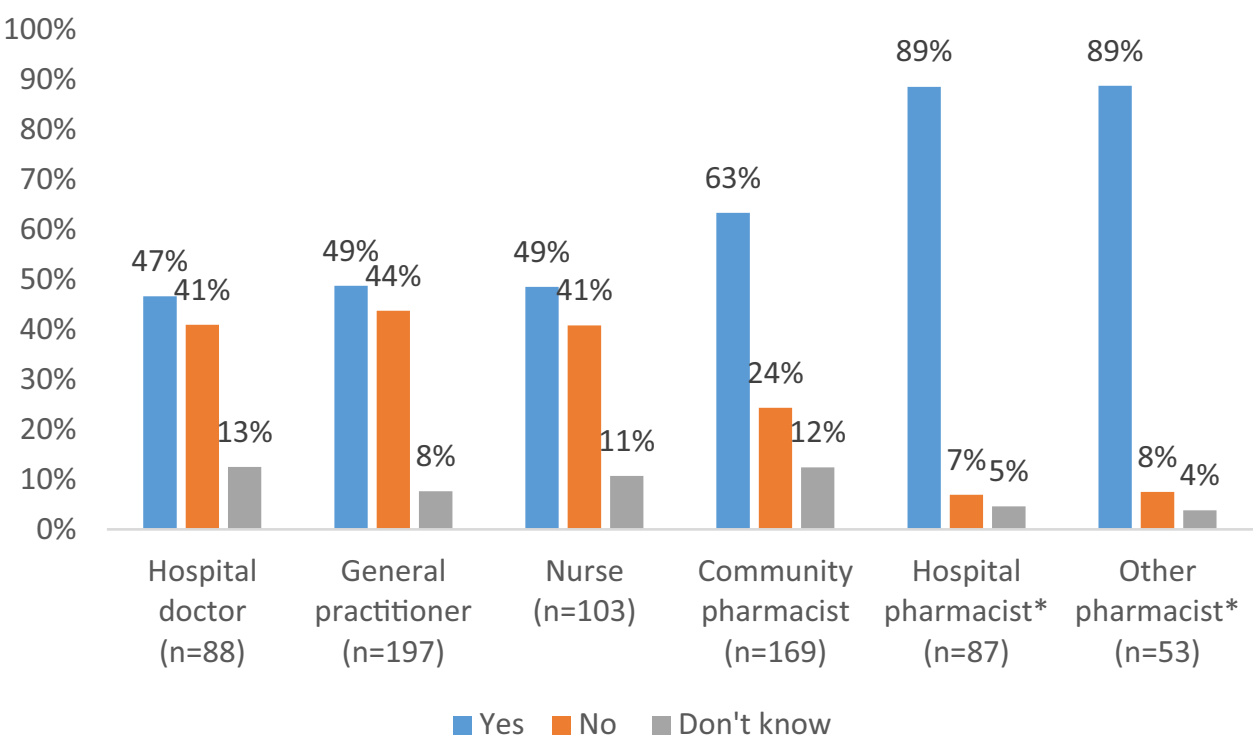

Interestingly, 16 respondents $(2.3 \%)$ indicated that they were familiar with the term biosimilar medicine but not with the term biological medicine.

\subsection{Knowledge of Pharmacovigilance Considerations for Biological Medicines}

Overall responses to knowledge items relating to the pharmacovigilance of biologicals are presented in Table 5 and the sub-group analysis is presented in Table S5 (see ESM). The average knowledge scores across all eight items was 5.85 correct items out of 8 (SD 1.78). Responses to some of the individual knowledge items (Table S5, see ESM) varied across HCP groups and this is indicated by differences in mean knowledge scores between groups $(p<0.001$, one-way ANOVA) (Table 3).

In order to confirm questionnaire robustness, mean knowledge scores of those familiar and those not familiar with the term 'biological medicine' were compared. Mean knowledge scores were significantly higher among those claiming to be familiar with the term 'biological medicine' (6.08, SD 1.70) compared with those who were not familiar with the term $(4.88$, SD 1.78) $(p<0.001$, independent $t$ test).

\subsection{Traceability of Biologicals}

The majority of respondents $(73 \%, n=504)$ answered that biological medicines were prescribed/dispensed or administered in their practice (Table 1). HCPs who used biologicals were asked questions pertaining to their traceability. The majority confirmed that they generally recorded details of biological medicines by brand name
(Table S6, see ESM). Respondents were asked if, in their practice, batch numbers of biological medicines that were administered/dispensed to patients were generally recorded. Practice behaviours were observed to differ between professions (Fig. 3), although large proportions of hospital doctors (39\%) and nurses (24\%) were unable to answer this question. Respondents who indicated that their batch number recording practices varied by medicine were asked to give specific examples. A variety of responses were given; examples included batch number recording for specific monoclonal antibodies, vaccines, blood-derived medicines, or medicines that were aseptically compounded by the pharmacy.

ADR reports for biological medicines containing filgrastims, epoetins and infliximab were extracted from the HPRA database and analysed for inclusion of brand name and batch number details (Fig. 4). High levels of brand name reporting were observed with lower levels of batch number reporting, which varied across product types. As some reports arose from literature/clinical trial settings, follow-up to identify brand name or batch number would not have been feasible.

HCPs who used biological medicines in their practice were asked to rate the value of brand name and batch number recording on two different scales. The mean score for batch number recording on a 7-point scale anchored by 'worthless (1) to valuable (7)' was 5.47 (SD 1.65), suggesting that HCPs perceive batch number recording as valuable. However, on a 7-point scale anchored by 'easy (1) to difficult (7)', HCPs perceived batch number recording (4.61, SD 2.04) to be more difficult than brand name recording (3.60, SD 2.25) (Table S7, see ESM). 
Table 4 Familiarity with the terms 'biological medicine' and 'biosimilar medicine' among healthcare professional groups

\begin{tabular}{|c|c|c|c|}
\hline Profession & $n$ & Familiar $^{\mathrm{a}}$ & Not familiar ${ }^{b}$ \\
\hline \multicolumn{4}{|c|}{ Familiarity with the term biological medicine } \\
\hline Hospital doctor & 88 & 90.9 & 9.1 \\
\hline General practitioner $^{\mathrm{c}}$ & 197 & 80.2 & 19.8 \\
\hline Nurse $^{d}$ & 103 & 45.6 & 54.4 \\
\hline Community pharmacist & 169 & 87.0 & 13.0 \\
\hline Hospital pharmacist & 87 & 95.4 & 4.6 \\
\hline Other pharmacist & 53 & 100 & 0 \\
\hline Total & 697 & 81.4 & 18.5 \\
\hline \multicolumn{4}{|c|}{ Familiarity with the term biosimilar medicine } \\
\hline Hospital doctor & 88 & 69.3 & 30.7 \\
\hline General practitioner ${ }^{\mathrm{e}}$ & 197 & 47.2 & 52.8 \\
\hline Nurse $^{f}$ & 104 & 26.9 & 73.1 \\
\hline Community pharmacist & 169 & 79.9 & 20.1 \\
\hline Hospital pharmacist ${ }^{\mathrm{g}}$ & 87 & 95.4 & 4.6 \\
\hline Other pharmacist $\mathrm{t}^{\mathrm{h}}$ & 53 & 98.1 & 1.9 \\
\hline Total & 698 & 64.8 & 35.2 \\
\hline
\end{tabular}

Awareness rates compared using Chi square test for independence. A Bonferroni correction was applied

$H C P$ healthcare professional

${ }^{a} \mathrm{HCPs}$ responded that they were 'very familiar - complete understanding' or 'familiar - basic understanding'

'HCPs responded that they had 'heard of the term - can't define it' or 'never heard of the term'

${ }^{\text {c} G e n e r a l ~ p r a c t i t i o n e r s ~ w e r e ~ l e s s ~ f a m i l i a r ~ w i t h ~ t h e ~ t e r m ~ ' b i o l o g i c a l ~}$ medicine' than hospital pharmacists and 'other pharmacists' ( $p=0.002$ and $p<0.001$, respectively)

${ }^{\mathrm{d} N u r s e s}$ were less familiar with the term 'biological medicine' than all other HCP groups $(p<0.001$ in all cases)

${ }^{\mathrm{e}} \mathrm{General}$ practitioners were less familiar with the term 'biosimilar medicine' than hospital doctors and community pharmacists ( $p=0.001$ and $p<0.001$, respectively)

fNurses were less familiar with the term 'biosimilar medicine' than all other HCP groups ( $p \leq 0.001$ in all cases)

${ }^{\mathrm{g}}$ Hospital pharmacists were more familiar with the term 'biosimilar medicine' than hospital doctors, general practitioners and community pharmacists $(p<0.001, p<0.001$ and $p=0.002$, respectively)

h'Other' pharmacists were more familiar with the term 'biosimilar medicine' than hospital doctors, general practitioners and community pharmacists $(p<0.001, p<0.001$ and $p=0.003$, respectively)

\subsection{Additional Monitoring}

The majority of HCPs were aware of the concept of additional monitoring, however awareness rates differed between some groups (Table 6). A total of 568 HCPs claimed to know about additional monitoring, but among this number there were differences in awareness of the inverted black triangle across HCP groups. In particular, pharmacists had higher awareness of the black triangle than hospital doctors, GPs and nurses (Table 6).

Those who knew about additional monitoring were asked if they were aware when this applied to medicines used in their practice. Of this number, $39.7 \%(n=225)$ were frequently or always aware, $36.4 \%(n=207)$ were sometimes aware and $23.7 \%(n=134)$ were never or rarely aware.

Among HCPs who worked directly with patients $(n=506)$, over half $(57.9 \%, n=293)$ indicated that they never or rarely informed patients when their medicines were subject to additional monitoring. The subgroup analysis is provided in Table S8 (see ESM).

\section{Discussion}

There are no recent studies assessing knowledge of ADR reporting among HCPs in Ireland. More generally, it is not known whether HCPs in Europe are aware of 'additional monitoring'. Although issues associated with the pharmacovigilance of biological medicines are well documented, again it is not known to what degree HCPs are cognisant of these issues. A cross-sectional survey of HCPs in Ireland was conducted in order to address these knowledge gaps.

The majority of HCPs were aware that ADRs could be reported directly to the Regulatory Authority in Ireland. However, nurses were less aware than other groups, supporting recent conclusions by de Angelis et al. [29] that nurses are not fully aware of their role in ADR reporting. Nurses are responsible for drug administration and record keeping, and of all the HCP groups surveyed, nurses may often have the most contact with patients, making them more likely to be present when an ADR occurs or is identified [30]. ADR reports from nurses have been shown to be valuable and of acceptable quality [31, 32], thus corroborating the important contribution nurses can make to pharmacovigilance and highlighting the need to increase awareness about ADR reporting among nurses. On the other hand, hospital pharmacists had the most experience of ADR reporting, echoing findings from a US study that found that pharmacists in general were more likely to have reported an ADR in the past than hospital doctors [5]. Our results suggest that pharmacy practice setting is an important determinant of ADR reporting experience. Hospital pharmacists had significantly more experience with ADR reporting than community pharmacists, and the proportion of non-reporters among community pharmacists was in fact similar to the proportion of non-reporters among hospital doctors and GPs. The important contribution made by hospital pharmacists to ADR reporting is also confirmed when ADR reports made directly to the HPRA by HCPs are considered. Over a 5-year period, the number 
Table 5 Pharmacovigilance considerations for biological medicines: response to individual knowledge items

\begin{tabular}{|c|c|c|c|c|}
\hline Question $^{\mathrm{a}}$ & $n$ & $\begin{array}{l}\% \\
\text { correct }\end{array}$ & $\begin{array}{l}\% \\
\text { incorrect }\end{array}$ & $\begin{array}{l}\% \text { don't } \\
\text { know }\end{array}$ \\
\hline $\begin{array}{l}\text { ADRs associated with a patient changing between different brands of biological medicines should be } \\
\text { reported (yes) }\end{array}$ & 694 & 92.1 & 1.0 & 6.9 \\
\hline $\begin{array}{l}\text { In an ADR report it is better to identify a biological medicine by its non-proprietary name (e.g. insulin } \\
\text { glargine) instead of its brand name (no) }\end{array}$ & 695 & 59.9 & 27.3 & 12.8 \\
\hline Biosimilars are the same as generic medicines (no) & 693 & 75.2 & 10.7 & 14.1 \\
\hline $\begin{array}{l}\text { Rare ADRs resulting from changes to the manufacturing process of a biological medicine can always be } \\
\text { predicted (no) }\end{array}$ & 696 & 82.9 & 1.3 & 15.8 \\
\hline $\begin{array}{l}\text { Keeping a biological medicine outside its recommended storage conditions may introduce or alter } \\
\text { immunogenicity (yes) }\end{array}$ & 694 & 80.1 & 1.0 & 18.9 \\
\hline Different batches of the same biological medicine are always identical (no) & 695 & 71.4 & 7.9 & 20.7 \\
\hline $\begin{array}{l}\text { It is more important to include batch numbers in ADR reports for non-biological medicines than it is for } \\
\text { biological medicines (no) }\end{array}$ & 693 & 61.3 & 17.7 & 20.9 \\
\hline $\begin{array}{l}\text { In general, biological medicines pose a greater risk of immunogenicity than non-biological (chemical) } \\
\text { medicines (yes) }\end{array}$ & 693 & 61.9 & 7.6 & 30.4 \\
\hline
\end{tabular}

$A D R$ adverse drug reaction

${ }^{\mathrm{a} C}$ Correct answer is shown in brackets

Fig. 3 Batch number recording of biological medicines. Survey question: "In your practice are the batch numbers of biological medicines that have been administered/dispensed to patients generally recorded?"

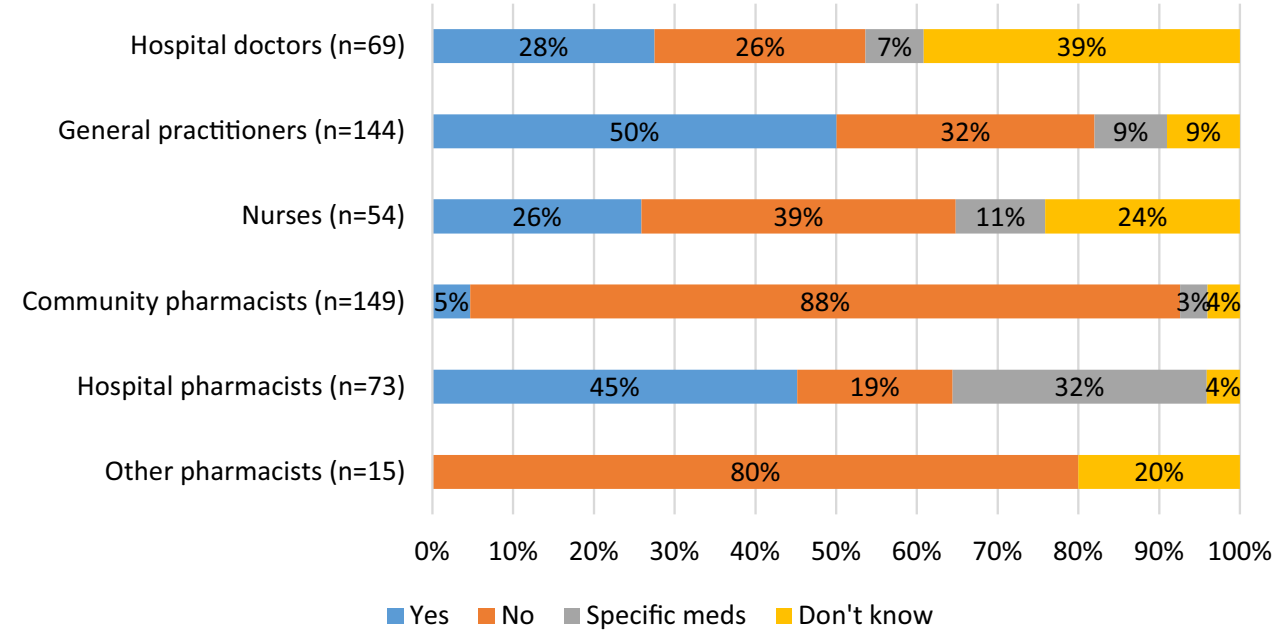

Previous research suggests that knowledge of ADR reporting among HCPs could be improved [19-21, 23, 35]. Knowledge was measured using eight items (Table 2) and correct answers for four of the knowledge items were high (> 78\%). Importantly, most HCPs know that individual ADR reports are capable of contributing to knowledge on medicine risks. This is reassuring, considering that individual ADR reports can lead to re-evaluation of benefitrisk balances for medicines [36]. Interestingly, almost one in three HCPs $(31.0 \%)$ did not know that patients can report ADRs independent of a HCP. Although research on the impact of patient ADR reporting is limited [37], reports from patients do offer a different perspective from HCP reports, are more detailed [37-40] and contribute to safety signals [41]. The 'other' pharmacist group had the highest
${ }^{1}$ Personal communication with the Pharmaceutical Society of Ireland. 
Fig. 4 Percentage of reports submitted to the Health Products Regulatory Authority that contained brand name and batch number details for biological medicines containing filgrastim, epoetin and infliximab over a 5 -year period (2013-2017)

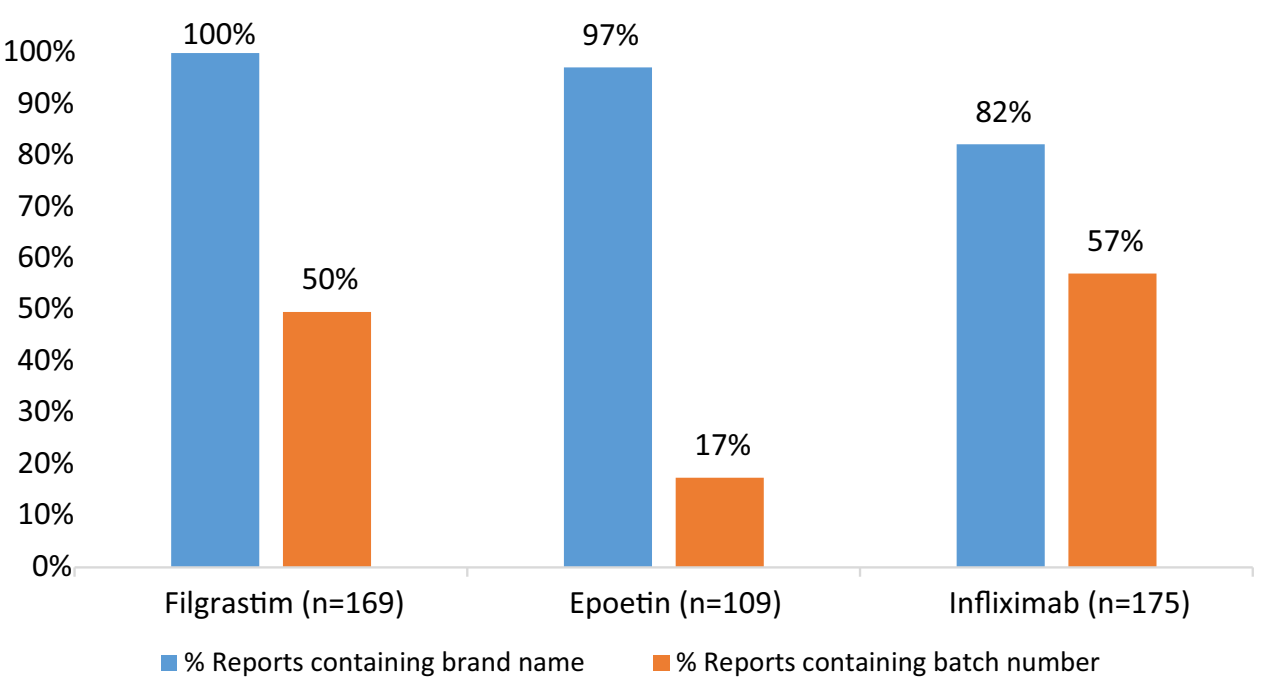

mean knowledge scores on ADR reporting (Table 3), reflecting the fact that many of this group worked in the pharmaceutical industry $(41.5 \%)$ and medicines regulation (13.2\%). Among practising HCPs, hospital pharmacists had the highest mean knowledge scores, which is also reflected in the fact that they have the most experience with ADR reporting. Indeed, hospital pharmacists and 'other' pharmacists were more confident in their own knowledge of ADR reporting than other HCP groups (Fig. 2).

More hospital doctors, nurses and GPs were familiar with the term 'biological medicine' than with the term 'biosimilar medicine' (Table 4). This could reflect the fact that Ireland has low uptake of biosimilar medicines compared with other European countries [13, 42, 43]. Familiarity with the term biosimilar differed among HCP groups (Table 4). For instance, fewer community pharmacists (79.9\%) were familiar with the term 'biosimilar medicine' than hospital pharmacists (95.4\%), corroborating findings from a 2015 survey carried out in France, where a higher proportion of community pharmacists responded that they were not at all informed about biosimilars compared with hospital pharmacists [44]. A survey of HCPs conducted in Ireland the year before this current study (2016) found similar proportions of GPs and community pharmacists claimed they were familiar with the term biosimilar. However, there were higher familiarity rates among hospital doctors in the earlier survey, which may be attributed to the fact that this survey was conducted among doctors who worked in specialities where biological medicines are commonly used [13].

Knowledge of the pharmacovigilance of biological medicines was measured using eight items (Table 5). A sizeable proportion of HCPs $(30.4 \%, n=211)$ did not know that biological medicines pose a greater risk of immunogenicity than non-biological medicines. This is concerning, considering that rare events related to immunogenicity may rely heavily on ADR reports from observant HCPs [12]. Almost one in five $(18.9 \%, n=131)$ did not know that keeping a biological outside its recommended storage conditions could introduce or alter immunogenicity, suggesting that the importance of storage and handling requirements for biologicals need to be better communicated. Interestingly, statements relating to traceability of biologicals had the lowest proportions of correct answers. Knowledge gaps relating to the inclusion of brand names and batch numbers in biological ADR reports were identified. Knowledge of biological pharmacovigilance was also observed to differ among HCP groups, with hospital pharmacists and hospital doctors having higher mean knowledge scores than GPs and nurses (Table 3).

The EMA advise that the brand name and batch numbers of biologicals are recorded at all levels in the medicines supply chain, including prescription, dispensing and patient administration [9]. HCPs indicated that they generally recorded biologicals by brand name (Table S6, see ESM), reflecting the fact that electronic information recording systems in Ireland generally default to brand name recording. Traceability to batch level was lower and recording practices differed between some professions (Fig. 3). These recording practices are reflected in ADR reports submitted directly to the HPRA. Analysis of reports for certain biological medicines indicated high levels of brand name inclusion in ADR reports with lower levels of batch number reporting (Fig. 4). However, the levels of batch number traceability in ADR reports were higher than levels seen in other European spontaneous ADR databases $[17,45,46]$. This may reflect efforts made by the HPRA to (i) actively inform HCPs about ADR reporting requirements and (ii) follow-up with reporters for missing information. Nevertheless, the results indicate that information recording systems in Ireland may not fully support batch traceability of biologicals. In Irish hospitals, clinical 
Table 6 Awareness of additional monitoring among healthcare professionals

\begin{tabular}{|c|c|c|}
\hline Profession & $n$ & Percentage aware \\
\hline \multicolumn{3}{|c|}{ Proportion aware of additional monitoring ${ }^{\mathrm{a}}$} \\
\hline Hospital doctor & 88 & 84.1 \\
\hline General practitioner $^{\mathrm{b}}$ & 197 & 67.0 \\
\hline Nurse $^{c}$ & 104 & 71.2 \\
\hline Community pharmacist & 168 & 91.7 \\
\hline Hospital pharmacist & 87 & 96.6 \\
\hline Other pharmacist & 53 & 94.3 \\
\hline Total & 697 & 81.5 \\
\hline \multicolumn{3}{|c|}{ Proportion aware of black triangle ${ }^{\mathrm{d}}$} \\
\hline Hospital doctor & 74 & 35.1 \\
\hline General practitioner & 132 & 35.6 \\
\hline Nurse $^{\mathrm{e}}$ & 74 & 14.9 \\
\hline Community pharmacist $\mathrm{f}^{\mathrm{f}}$ & 154 & 86.4 \\
\hline Hospital pharmacist ${ }^{\mathrm{g}}$ & 84 & 88.1 \\
\hline Other pharmacist $^{\mathrm{h}}$ & 50 & 94.0 \\
\hline Total & 568 & 59.5 \\
\hline
\end{tabular}

Awareness rates compared using Chi square test for independence. A Bonferroni correction was applied

${ }^{\text {a }}$ Survey question: "Prior to this survey were you aware that some medicines are subject to additional monitoring" (Brief explanation of additional monitoring provided)

${ }^{\mathrm{b}}$ General practitioners had lower awareness rates of additional monitoring than community, hospital and 'other' pharmacist groups $(p<0.001$ in all cases)

${ }^{c}$ Nurses had lower awareness rates of additional monitoring than community, hospital and 'other' pharmacist groups $(p<0.001$, $p<0.001$ and $p=0.002$, respectively)

${ }^{\mathrm{d}}$ Survey question: "Prior to this survey did you know that when a medicine is subject to additional monitoring an inverted black triangle symbol $\boldsymbol{\nabla}$ appears beside the name of the medicine in the summary of product characteristics and package leaflet?" (this question was only asked to those who previously responded that they were aware of additional monitoring)

${ }^{\mathrm{e}}$ Nurses had lower awareness rates of the black triangle than general practitioners $(p<0.001)$

${ }^{\mathrm{f}}$ Community pharmacists had higher awareness rates of the black triangle than hospital doctors, general practitioners and nurses $(p<0.001$ in all cases $)$

${ }^{\mathrm{g}}$ Hospital pharmacists had higher awareness rates of the black triangle than hospital doctors, general practitioners and nurses $(p<0.001$ in all cases)

h'Other' pharmacists had higher awareness rates of the black triangle than hospital doctors, general practitioners and nurses $(p<0.001$ in all cases)

records are almost exclusively paper based, so manual recording of batch number is necessary. In pharmacies, there is no prompt for dispensing pharmacists to manually record batch number details.

The person responsible for ADR reporting is likely to vary according to the practice setting and ADR reporting processes in place. Inclusion of the brand name and batch number in an ADR report depends on availability of the original packaging, whether exposure information is routinely recorded in medical, nursing or pharmacy records, and whether the reporter has access to such records [18]. Willingness to report this information could also be an influencing factor. HCPs were asked to rate brand and batch number recording on scales anchored by worthless (1) to valuable (7) and easy (1) to difficult (7). The results show that HCPs perceive batch number recording as valuable but also that recording batch numbers is difficult. Steps aimed at improving batch number traceability [18] of biologicals in Ireland and elsewhere are needed. Traceability needs to be fully integrated into healthcare settings. For instance, future information recording systems, including the roll-out of seamless electronic patient health records, could be designed to allow automatic recording of brand and batch details upon dispensing and administration. Record linkage would also ensure that ADR reporters have access to the necessary information.

The majority of respondents were aware of additional monitoring (Table 6). However, awareness of the black triangle symbol $\boldsymbol{\nabla}$ that appears on the SmPC and the PL was much higher among the three pharmacist groups than among other HCPs. This suggests that the black triangle is an effective way of communicating the additional monitoring status of a medicine to pharmacists. However, improved communication on the meaning of the black triangle is needed for hospital doctors, nurses and GPs. Over half of HCPs $(57.9 \%, n=293)$ who worked directly with patients and who knew about additional monitoring never or rarely informed patients when their medicines were subject to additional monitoring (Table S8, see ESM). HCPs are considered an effective medium to inform patients about additional monitoring [47] and are in a position to encourage ADR reporting from patients [40, 48]. Improving HCP awareness of the value of ADR reporting by patients and encouragement of HCPs to inform their patients about medicines subject to additional monitoring may be a mechanism by which additional safety information can be gathered.

This study revealed some differences in knowledge and experience of ADR reporting among a diverse group of HCPs. It is important that all HCPs involved in the care of patients receiving medicines are appropriately informed and empowered to contribute to the ongoing safety monitoring of medicines. Different strategies have been applied in order to address underreporting and to improve knowledge of and attitudes to pharmacovigilance $[49,50]$. Sustained education and training [51] will enable HCPs to keep abreast of changes such as the introduction of additional monitoring of medicines. For example, specific education [52] and practical training (e.g. ADR reporting assignments) [31] for nurses is likely to encourage ADR 
reporting from this cohort. Further to improving ADR reporting, the increasing availability of biological medicines, including biosimilars, make it necessary for HCPs to implement appropriate practice behaviours in order to ensure their traceability. As such, education on biological medicines needs to be incorporated at undergraduate level and beyond. The use of sustained awareness campaigns on importance of ADR reporting including traceability issues for biological medicines, along with further research into appropriate educational interventions is warranted.

Low response rates were the main limitation of this survey. However, in the case of GPs, the response rate was not unexpected as we received similar response rates using the same method of dissemination in a survey conducted the year previously [13]. Response rates for nurses could not be calculated owing to the method of survey distribution. Although non-response biases must be considered in the interpretation of the results, this is a large multidisciplinary study from which the results may be generalisable to other European countries where the same regulations and similar HCP education standards apply. There were baseline differences among the practising HCPs in terms of reported experience with biologicals. The majority of hospital doctors, GPs, community and hospital pharmacists responded that they used biological medicines in their practice. However, this proportion was lower for nurses as just over half answered that biological medicines were used and one in four indicated that they did not know. Respondent location and educational institution may have impacted responses received and this was not explored in the current study. Questions pertaining to knowledge of the HPRA (Q12, see ESM) and awareness of additional monitoring (Q15 and Q16, see ESM) were phrased "Prior to this survey did you know...". This may have introduced some bias as it depended on the HCP reflection on their own prior knowledge. Finally, an analysis of the HPRA ADR database was conducted in order to determine traceability details in reports for specific biological medicines, this may not be representative of overall traceability of biologicals in ADR reports received by the HPRA.

\section{Conclusion}

A substantial proportion of hospital doctors, GPs, nurses and community pharmacists were found to lack confidence in their own knowledge of ADR reporting, highlighting the importance of ongoing HCP education and training in the area of pharmacovigilance. Among practising HCPs, hospital pharmacists had the most experience and highest mean knowledge scores related to ADR reporting. This highlights the important contribution hospital pharmacists make to post-marketing surveillance. Although awareness of additional monitoring is high, poor knowledge of the inverted black triangle among hospital doctors, GPs and nurses suggest that alternative methods to alert these groups of the additional monitoring status of a medicine may be warranted. One in three HCPs were unaware that patients could report ADRs. Improved HCP awareness of the contribution patients make to ADR reporting may help generate additional safety data, especially for medicines subject to additional monitoring. There appears to be a knowledge gap relating to immunogenicity, storage and the traceability of biological medicines for the purpose of ADR reporting. HCPs in Ireland perceive that recording batch numbers for biological medicines is valuable, but they also perceive that the recording of batch numbers is more difficult than the recording of brand names. Further research and measures to improve batch traceability of biologicals in healthcare settings are needed.

Acknowledgements The following groups are thanked for providing advice and access to their network: Irish College of General Practitioners, Royal College of Physicians in Ireland, Pharmaceutical Society of Ireland and the Office of Nursing and Midwifery Services, Health Service Executive. The authors wish to thank the following for advice with this study: Colleagues in Human Products MonitoringHealth Products Regulatory Authority (HPRA), Una Moore (HPRA), Sean Barry (HPRA), Maeve Lally (HPRA), Jeanette Mc Callion (HPRA), Anna Cunney (HPRA), Olive Smyth (HPRA), Rebecca Cramp (IPHA), Colm Galligan (MSD), Syzana Hasani (AbbVie), Sean Leavey, Sinead Kelly, Lisa Fagan and Claire Collins.

\section{Compliance with Ethical Standards}

Funding This work was supported by the Health Products Regulatory Authority (HPRA), Regulatory Science Ireland and University College Cork. Brendan T. Griffin is also supported in part by the Irish Pharmaceutical Healthcare Association (IPHA) in the form of a research grant to support regulatory science research. Open access publication of this article was funded by the Irish Pharmaceutical Healthcare Association (IPHA) in the form of a research grant to support regulatory science research.

Conflict of interest Joan O'Callaghan, Brendan T. Griffin, J. Michael Morris and Margaret Bermingham declare that they have no conflict of interest.

Open Access This article is distributed under the terms of the Creative Commons Attribution-NonCommercial 4.0 International License (http://creativecommons.org/licenses/by-nc/4.0/), which permits any noncommercial use, distribution, and reproduction in any medium, provided you give appropriate credit to the original author(s) and the source, provide a link to the Creative Commons license, and indicate if changes were made.

\section{References}

1. Wise L, Parkinson J, Raine J, Breckenridge A. New approaches to drug safety: a pharmacovigilance tool kit. Nat Rev Drug Discov. 2009;8(10):779-82. 
2. Alvarez Y, Hidalgo A, Maignen F, Slattery J. Validation of statistical signal detection procedures in eudravigilance post-authorization data: a retrospective evaluation of the potential for earlier signalling. Drug Saf. 2010;33(6):475-87.

3. Hazell L, Shakir SA. Under-reporting of adverse drug reactions : a systematic review. Drug Saf. 2006;29(5):385-96.

4. Lopez-Gonzalez E, Herdeiro MT, Figueiras A. Determinants of under-reporting of adverse drug reactions: a systematic review. Drug Saf. 2009;32(1):19-31.

5. Stergiopoulos S, Brown CA, Felix T, Grampp G, Getz KA. A survey of adverse event reporting practices among US healthcare professionals. Drug Saf. 2016;39(11):1117-27.

6. Borg JJ, Aislaitner G, Pirozynski M, Mifsud S. Strengthening and rationalizing pharmacovigilance in the EU: where is Europe heading to? A review of the new EU legislation on pharmacovigilance. Drug Saf. 2011;34(3):187-97.

7. European Medicines Agency (EMA). Guideline on good pharmacovigilance practices (GVP) module $\mathrm{X}$-additional monitoring. 2013. http://www.ema.europa.eu/docs/en_GB/document_ library/Scientific_guideline/2013/04/WC500142282.pdf. Accessed 4 Jan 2018.

8. European Parliament and Council of Europe. Directive 2001/83/ EC of the European Parliament and of the Council of November 2001 on the Community Code Relating to Medicinal Products for Human Use (consolidated version). http://ec.europa.eu/health/ files/eudralex/vol-1/dir_2001_83_consol_2012/dir_2001_83_cons_ 2012_en.pdf. Accessed 5 Jan 2018.

9. European Medicines Agency (EMA). Guideline on good pharmacovigilance practices (GVP) product- or population-specific considerations II: biological medicinal products, EMA/168402/ 2014. 2016. http://www.ema.europa.eu/docs/en_GB/document_ library/Scientific_guideline/2016/08/WC500211728.pdf. Accessed 20 Jan 2018.

10. Schneider CK. Biosimilars in rheumatology: the wind of change. Ann Rheum Dis. 2013;72(3):315-8.

11. Schiestl M, Stangler T, Torella C, Cepeljnik T, Toll H, Grau R. Acceptable changes in quality attributes of glycosylated biopharmaceuticals. Nat Biotechnol. 2011;29(4):310-2.

12. Ebbers HC, Mantel-Teeuwisse AK, Moors EH, Schellekens H, Leufkens HG. Today's challenges in pharmacovigilance: what can we learn from epoetins? Drug Saf. 2011;34(4):273-87.

13. O'Callaghan J, Bermingham M, Leonard M, Hallinan F, Morris $\mathrm{JM}$, Moore $\mathrm{U}$, et al. Assessing awareness and attitudes of healthcare professionals on the use of biosimilar medicines: a survey of physicians and pharmacists in Ireland. Regul Toxicol Pharmacol. 2017;27(88):252-61.

14. European Medicines Agency (EMA). Guideline on similar biological medicinal products. 2014. http://www.ema.europa.eu/ docs/en_GB/document_library/Scientific_guideline/2014/10/ WC500176768.pdf. Accessed 4 Jan 2018.

15. Food and Drug Administration (FDA). Nonproprietary naming of biological products guidance for industry. 2017. https://www.fda. gov/downloads/Drugs/GuidanceComplianceRegulatoryInforma tion/Guidances/UCM459987.pdf. Accessed 5 Jan 2018.

16. Ramanan S, Grampp G. Drift, evolution, and divergence in biologics and biosimilars manufacturing. BioDrugs. 2014;28(4):363-72.

17. Vermeer NS, Straus SM, Mantel-Teeuwisse AK, Domergue F, Egberts TC, Leufkens HG, et al. Traceability of biopharmaceuticals in spontaneous reporting systems: a cross-sectional study in the FDA adverse event reporting system (FAERS) and EudraVigilance databases. Drug Saf. 2013;36(8):617-25.

18. Vermeer NS, Spierings I, Mantel-Teeuwisse AK, Straus SM, Giezen TJ, Leufkens HG, et al. Traceability of biologicals: present challenges in pharmacovigilance. Expert Opin Drug Saf. 2015;14(1):63-72.
19. Gavaza P, Brown CM, Lawson KA, Rascati KL, Wilson JP, Steinhardt M. Texas pharmacists' knowledge of reporting serious adverse drug events to the Food and Drug Administration. J Am Pharm Assoc. 2011;51(3):397-403.

20. Biagi C, Montanaro N, Buccellato E, Roberto G, Vaccheri A, Motola D. Underreporting in pharmacovigilance: an intervention for Italian GPs (Emilia-Romagna region). Eur J Clin Pharmacol. 2013;69(2):237-44.

21. Ekman E, Petersson G, Tågerud S, Bäckström M. Awareness among nurses about reporting of adverse drug reactions in Sweden. Drug Healthc Patient Saf. 2012;4:61-6.

22. Santosh KC, Tragulpiankit P, Edwards IR, Gorsanan S. Knowledge about adverse drug reactions reporting among healthcare professionals in Nepal. Int J Risk Saf Med. 2013;25(1):1-16.

23. Dorji C, Tragulpiankit P, Riewpaiboon A, Tobgay T. Knowledge of adverse drug reaction reporting among healthcare professionals in Bhutan: a cross-sectional survey. Drug Saf. 2016;39(12):1239-50.

24. Schutte T, Tichelaar J, Reumerman MO, van Eekeren R, Rissmann R, Kramers C, et al. Pharmacovigilance skills, knowledge and attitudes in our future doctors - a nationwide study in the Netherlands. Basic Clin Pharmacol Toxicol. 2017;120(5):475-81.

25. Gavaza P, Bui B. Pharmacy students' attitudes toward reporting serious adverse drug events. Am J Pharm Educ. 2012;76(10):194.

26. Dolinar RO, Reilly MS. Biosimilars naming, label transparency and authority of choice-survey findings amongst European physicians. Generics Biosimilars Initiat $\mathrm{J}$ ( $\mathrm{GaBI} J$ ). 2014;3(2):58-62.

27. Gavaza P, Brown CM, Lawson KA, Rascati KL, Wilson JP, Steinhardt M. Examination of pharmacists' intention to report serious adverse drug events (ADEs) to the FDA using the theory of planned behavior. Res Soc Adm Pharm. 2011;7(4):369-82.

28. Health Products Regulatory Authority (HPRA). Health products regulatory authority website. 2018. https://www.hpra.ie/. Accessed 13 Mar 2018.

29. De Angelis A, Colaceci S, Giusti A, Vellone E, Alvaro R. Factors that condition the spontaneous reporting of adverse drug reactions among nurses: an integrative review. $J$ Nurs Manag. 2016;24(2):151-63.

30. Hall M, McCormack P, Arthurs N, Feely J. The spontaneous reporting of adverse drug reactions by nurses. Br J Clin Pharmacol. 1995;40(2):173-5.

31. Schutte T, van Eekeren R, Richir M, van Staveren J, van Puijenbroek E, Tichelaar J, et al. The adverse drug reaction reporting assignment for specialist oncology nurses: a preliminary evaluation of quality, relevance and educational value in a prospective cohort study. Naunyn Schmiedebergs Arch Pharmacol. 2018;391(1):17-26.

32. Oosterhuis I, Rolfes L, Ekhart C, Muller-Hansma A, Härmark L. First experiences with a tool to measure the level of clinical information present in adverse drug reaction reports. Expert Opin Drug Saf. 2018;17(2):111-5.

33. Health Service Executive (HSE). General practitioners or family doctors. 2018. https://www.hse.ie/eng/services/list/2/gp/. Accessed 13 Mar 2018.

34. An Roinn Slainte (Department of Health). Consultants, nonconsultant hospital doctors and nurses. 2018. http://health.gov.ie/ publications-research/statistics/statistics-by-topic/consultants-andnon-consultant-hospital-doctors/. Accessed 13 Mar 2018.

35. Irujo M, Beitia G, Bes-Rastrollo M, Figueiras A, Hernandez-Diaz $\mathrm{S}$, Lasheras B. Factors that influence under-reporting of suspected adverse drug reactions among community pharmacists in a Spanish region. Drug Saf. 2007;30(11):1073-82.

36. European Medicines Agency (EMA). Questions and answers on the recommendation to suspend the marketing authorisation for Raptiva. 2009. http://www.ema.europa.eu/docs/en_GB/ 
document_library/Medicine_QA/2009/11/WC500014492.pdf. Accessed 5 Oct 2017

37. Inacio $\mathrm{P}$, Cavaco A, Airaksinen $\mathrm{M}$. The value of patient reporting to the pharmacovigilance system: a systematic review. Br J Clin Pharmacol. 2017;83(2):227-46.

38. de Langen J, van Hunsel F, Passier A, de Jong-van den Berg L, van Grootheest K. Adverse drug reaction reporting by patients in the Netherlands: three years of experience. Drug Saf. 2008;31(6):515-24.

39. Aagaard L, Nielsen LH, Hansen EH. Consumer reporting of adverse drug reactions: a retrospective analysis of the Danish adverse drug reaction database from 2004 to 2006. Drug Saf. 2009;32(11):1067-74.

40. Avery AJ, Anderson C, Bond CM, Fortnum H, Gifford A, Hannaford PC, et al. Evaluation of patient reporting of adverse drug reactions to the UK 'Yellow Card Scheme': literature review, descriptive and qualitative analyses, and questionnaire surveys. Health Technol Assess. 2011;15(20):1-234 (iii-iv).

41. van Hunsel F, Talsma A, van Puijenbroek E, de Jong-van den Berg L, van Grootheest K. The proportion of patient reports of suspected ADRs to signal detection in the Netherlands: casecontrol study. Pharmacoepidemiol Drug Saf. 2011;20(3):286-91.

42. IMS Health. The impact of biosimilar competition. 2016. http:// ec.europa.eu/growth/tools-databases/newsroom/cf/itemdetail. cfm?item_id=8854. Accessed 5 Jan 2018.

43. IMS Health. The impact of biosimilar competition in Europe. 2017. http://ec.europa.eu/DocsRoom/documents/23102. Accessed 5 Jan 2018

44. Beck M, Michel B, Rybarczyk-Vigouret M-C, Levêque D, Sordet C, Sibilia J, et al. Knowledge, behaviors and practices of community and hospital pharmacists towards biosimilar medicines: results of a French web-based survey. MABS. 2017;9(2):384-91.
45. Klein K, Scholl JH, Vermeer NS, Broekmans AW, Van Puijenbroek EP, De Bruin ML, et al. Traceability of biologics in the Netherlands: an analysis of information-recording systems in clinical practice and spontaneous ADR reports. Drug Saf. 2016;39(2):185-92.

46. Cutroneo P, Isgrò V, Russo A, Ientile V, Sottosanti L, Pimpinella $\mathrm{G}$, et al. Safety profile of biological medicines as compared with non-biologicals: an analysis of the Italian spontaneous reporting system database. Drug Saf. 2014;37(11):961-70.

47. Strengthening Collaborations for Operating Pharmacovigilance in Europe (SCOPE). Identification, management and raising awareness of ADR reports for drugs subject to additional monitoring. 2016. http://www.scopejointaction.eu/outputsandresults/ adr-collection/additional-monitoring/. Accessed 5 Jan 2018.

48. Leone R, Moretti U, D'Incau P, Conforti A, Magro L, Lora R, et al. Effect of pharmacist involvement on patient reporting of adverse drug reactions: first Italian study. Drug Saf. 2013;36(4):267-76.

49. Gonzalez-Gonzalez C, Lopez-Gonzalez E, Herdeiro MT, Figueiras A. Strategies to improve adverse drug reaction reporting: a critical and systematic review. Drug Saf. 2013;36(5):317-28.

50. Pagotto C, Varallo F, Mastroianni P. Impact of educational interventions on adverse drug events reporting. Int $\mathrm{J}$ Technol Assess Health Care. 2013;29(4):410-7.

51. Steurbaut S, Hanssens Y. Pharmacovigilance: empowering healthcare professionals and patients. Int $\mathrm{J}$ Clin Pharm. 2014;36(5):859-62.

52. Backstrom M, Ekman E, Mjorndal T. Adverse drug reaction reporting by nurses in Sweden. Eur J Clin Pharmacol. 2007;63(6):613-8. 